\title{
Angiosarcoma of the liver: annual occurrence and aetiology in Great Britain
}

\author{
P J BAXTER, ${ }^{1}$ P P ANTHONY, ${ }^{2}$ R N M MACSWEEN, ${ }^{3}$ AND P J SCHEUER 4 \\ From the Health and Safety Executive, Employment Medical Advisory Service, ${ }^{1}$ London NW1 5DT, \\ the Area Department of Pathology, ${ }^{2}$ Exeter EX2 5DY, Western Infirmary, ${ }^{3}$ Glasgow G11 6NT, \\ and Royal Free Hospital, ${ }^{4}$ London NW3 $2 Q G, U K$
}

\begin{abstract}
The annual occurrence of angiosarcoma of the liver (ASL) in Britain from 1963 to 1977 was studied, including clinical and occupational details for those cases agreed as ASL by a panel of histopathologists. Thirty-five cases ( 28 men, six women, and one infant girl) were agreed as ASL. The increase in the incidence of ASL observed in recent years was attributable to Thorotrast(thorium dioxide) usage (eight cases) and exposure to vinyl chloride (two cases) in the past. In its clinical presentation and prognosis ASL resembled primary liver carcinoma, except that extrahepatic metastases were found in only eight $(23 \%)$ cases, and haemoperitoneum was more common in those cases due to Thorotrast. The results suggested a possible increased risk of ASL in the electrical and plastics fabrication industries, but information on exposure was inadequate to implicate specific chemicals. The clinical features of one case were indicative of arsenical intoxication, but medications in the other patients did not appear to be of aetiological importance.
\end{abstract}

We present our findings on the annual occurrence of angiosarcoma of the liver (ASL) in Britain during a 15-year period, 1963-77, and the clinical details of those cases agreed as ASL by a panel of pathologists. The role of known or suspected aetiological factors, ${ }^{1}$ including vinyl chloride, Thorotrast (thorium dioxide), inorganic arsenic and copper, and haemochromatosis, is also discussed. Many other chemicals occurring in the environment naturally or from industrial sources have been linked with liver tumours in animal studies, ${ }^{2}$ but the role of these substances in man remains to be resolved. The advantage of monitoring a tumour as rare in the general population as ASL is that it may be used as a marker tumour to identify human carcinogens, and we have adopted this approach.

\section{Method}

In 1974 an ASL register was set up in Britain by the Employment Medical Advisory Service (EMAS) of the Health and Safety Executive, and a preliminary report on the incidence of ASL in 1963-73, with details of the method of working of the panel, has been published. ${ }^{1}$ EMAS, in collaboration with the

Received 4 June 1979 Accepted 3 July 1979
Office for Population Censuses and Surveys (E:igland and Wales) and the General Register Office (Scotland), identifies recorded cases by the regular review of death certificates. The underlying cause of death is routinely coded by the Registrar General's staff under the International Classification of Diseases, 8th revision, as primary, secondary, or unspecified neoplasms of the liver and intrahepatic bile ducts (ICD numbers 155.0, 155.1, 197.7, 197.8, 211.5); neoplasms of unspecified nature of the liver and biliary passages (230.5); and haemangioma or lymphangioma (227). Additional sources of notifications are hospital pathologists, publications, and cancer registries (England and Wales only). Recorded cases are identified if any of the following diagnoses are mentioned: haemangio or angiosarcoma, Kupffer cell sarcoma, haemangioendothelioma, haemangioblastoma (adults only), or malignant angioma.

For all the recorded cases the hospital pathologists concerned are requested to send histological material from the tumour for review by a panel of three histopathologists (PPA, RNMMS, and PJS). Material for control purposes in the study of the 1974-7 cases of ASL was obtained from cases recorded as dying from other liver tumours (selected randomly from death certificates) or because the diagnosis was of special interest-for example, angioma, haemoperitoneum-or mentioned Thoro- 
trast. Sections from cases and controls are circulated in turn to the panel members who are unaware of the original diagnoses. Further details are to be found in the 1963-73 report. ${ }^{1}$ The histological appearances of ASL have been described, ${ }^{3}$ and a study of a large series of cases of different aetiology failed to find distinguishing morphological differences between them. ${ }^{4}$ Of all the known aetiological agents, a history of Thorotrast administration can be confirmed because particles of thorium dioxide are visible in tissue on light microscopy. In most cases the histological material was not suitable for comment on the non-neoplastic areas of liver tissue.

For cases agreed as ASL by the panel, attempts were made to obtain full medical records from hospital consultants and general practitioners, including information on medications, and clinical and necropsy details. For the earlier cases some records had already been destroyed. Occupational histories, including places of residence, were sought at an interview with the next-of-kin by an employment medical or nursing adviser using a standard questionnaire, which also asked for details of past illnesses, alcohol consumption, and tobacco smoking. The management or medical officers at places of work were requested to provide details of chemical exposures where appropriate; a history of exposure to vinyl chloride or PVC was specifically sought.

A mortality study of a series of Edinburgh patients who had received intra-arterial Thorotrast for cerebral angiography sometime between 1933 and 1948 was also undertaken. The results of this study will be described elsewhere. ${ }^{32}$

\section{Results}

For the period 1963-77 (Scotland 1965-77) death certificates meeting the required criteria were identified for 43 male and 25 female subjects, including one female and two male infants. A further 20 adult cases had either been reported to EMAS or published, ${ }^{156}$ including two deaths in 1963-73 which were missed in the earlier survey and identified through the Thorotrast study. ${ }^{32}$

Histological sections were received for $72(82 \%)$ of these recorded cases, and the panel agreed the diagnosis in $32(44 \%)$. Seven cases were regarded as doubtful, and four others as unclassifiable, the remainder being agreed as not ASL (table 1).

Three additional cases not shown in table 1 were identified among the control cases and agreed as ASL. In two of these the certified diagnosis was hepatic angioma; one had been diagnosed as ASL at necropsy, and the other was an infant girl with a necropsy diagnosis of infantile haemangioendothelioma. The diagnosis for the third control at necropsy
Table 1 Classification by panel of pathologists of all recorded cases of ASL occurring in Britain 1963-77

\begin{tabular}{|c|c|c|c|c|c|}
\hline & \multicolumn{2}{|c|}{$\begin{array}{l}\text { Death certificate } \\
\text { cases }\end{array}$} & \multicolumn{2}{|c|}{ Other cases* } & \multirow[t]{2}{*}{ Total } \\
\hline & Men & Women & Men & Women & \\
\hline No of patients & 43 & 25 & 14 & 6 & 88 \\
\hline $\begin{array}{l}\text { No seen by panel } \\
\text { Panel classification: }\end{array}$ & 33 & 20 & 14 & 5 & 72 \\
\hline ASL & 15 & 3 & 11 & 3 & 32 \\
\hline Doubtful & 2 & 2 & 2 & 1 & 7 \\
\hline Unclassifiable & 3 & 1 & 0 & 0 & 4 \\
\hline Not ASL & 13 & 14 & 1 & 1 & 29 \\
\hline
\end{tabular}

* Reported by hospital pathologists, publications, and cancer registries, and excluding three controls agreed as ASL.

and according to the death certificate was primary carcinoma of the liver, but was agreed as ASL by the panel; this patient had been identified through the Thorotrast study.

Thus altogether 35 cases ( $28 \mathrm{men}$, six women, one infant girl) were agreed by the panel as ASL. Of the cases identified in the death certificate search, the certificates had been coded under ICD nos 197.8 (nine cases), 155.0 (six cases), and 227 (three cases). The diagnoses according to the death certificate and ICD nos for those 17 agreed cases that had been identified from sources other than death certificates are shown in table 2; two of the certificates mentioned ASL. The commonest misleading diagnoses were hepatic cirrhosis, primary liver cancer, and hepatic angioma.

ANNUAL OCCURRENCE

The annual number of all recorded cases (including those found among the controls) was lower in most of the years before 1968 than after; and only two cases for 1963-7 were agreed as ASL by the panel (fig 1a). The number of cases rose to nine in 1969 and continued at a higher level than the earlier years

Table 2 Underlying cause of death and ICD number according to death certificates of 17 agreed cases of $A S L$ identified from other sources (including three controls)

\begin{tabular}{lll}
\hline Cause of death & ICD No & No of cases \\
\hline Hepatic cirrhosis & 571.9 & 4 \\
Primary liver tumour & 155.0 & 2 \\
Primary liver carcinoma & 155.0 & 1 \\
Hepatic angioma & 227 & 2 \\
Malignant liver tumour & 197.8 & 1 \\
Hepatic failure & 573 & 1 \\
Carcinomatosis & 199.0 & 1 \\
Perforated duodenal ulcer & 532.0 & 1 \\
Ovarian cyst & 220 & 1 \\
Ischaemic heart disease & 412.3 & 1 \\
Late effects of accidental injury & E 946 & 1 \\
Irradiation accident & E 948 & 1 \\
\hline
\end{tabular}




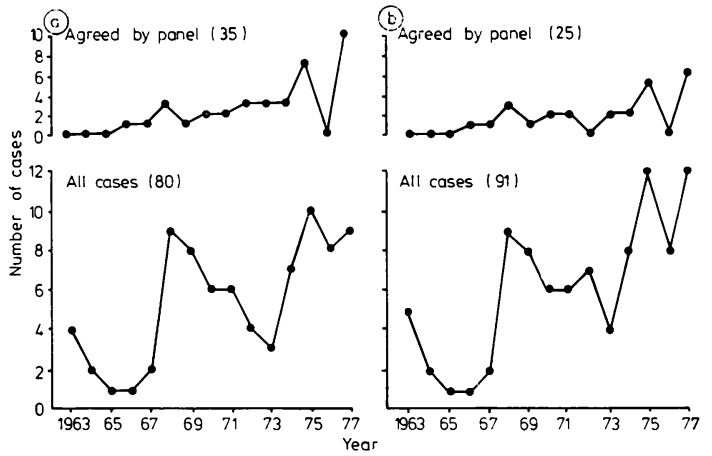

Fig 1(a) Annual incidence of all recorded cases (including three controls), and numbers of cases agreed as ASL by panel, 1963-77.

Fig 1(b) As in fig 1(a), but excluding cases of known aetiology.

until 1975 and 1977, when it rose to 12 in both years. The numbers of cases agreed by the panel remained at two to three a year until 1975 and 1977, when they rose to seven and nine respectively. If the cases of known aetiology (vinyl chloride and Thorotrast, to be described below) were removed from consideration an increasing incidence was not so apparent (fig 1b), suggesting that the rise had been due to a real increase in the number of cases rather than an improvement in case finding after publicity of the vinyl chloride problem in 1974. This interpretation is supported by the annual numbers of death certificates for ASL (figs $2 a$ and $b$ ). These did not
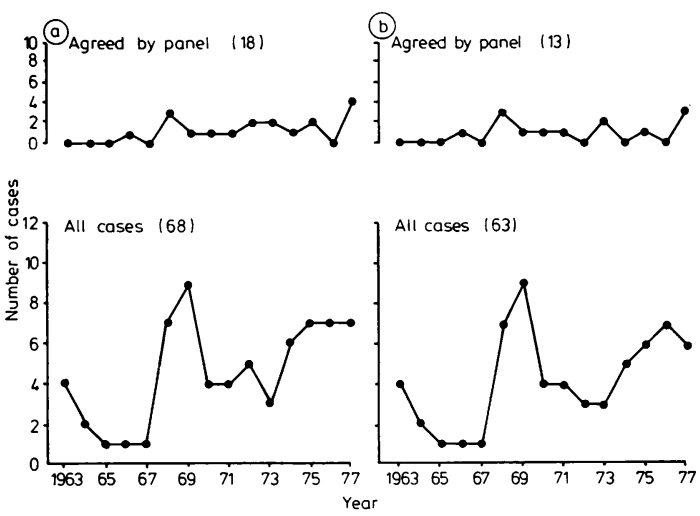

Fig 2(a) Annual incidence of all cases identified by death certificate search, and numbers of cases agreed as ASL by panel, 1963-77.

Fig 2(b) As in fig 2(a), but excluding cases of known aetiology. show the increase expected if national awareness had led to more recording of ASL. Also, in the prospective studies of Thorotrast patients ${ }^{32}$ and British workers exposed to vinyl chloride ${ }^{7}$ deaths from ASL have occurred only in recent years.

Taking the ten-year period $1968-77$ as being most representative, the annual number of cases in which no causal agents had been positively identified was fairly constant, both for the recorded cases and those agreed by the panel (figs $1 \mathrm{~b}$ and $2 \mathrm{~b}$ ). On average, seven cases a year were recorded from all sources, and among those for whom histological sections were obtainable, about two cases a year were agreed as ASL. For death certificate cases only, the average number of cases reported was five a year, with about one a year agreed by the panel.

\section{AGE DISTRIBUTION}

The distribution of the ages at death of the agreed cases of ASL is shown in fig 3; there was no apparent difference between cases of known and unknown aetiology, though the numbers of both were small. The mean age (and range) for men was $58 \cdot 3(30-78)$ years, and for women $65 \cdot 2(44-84)$ years; the infant girl died aged 8 months.

\section{SOCIAL CLASS}

For the male cases agreed as ASL, the occupations recorded on the death certificates were assigned to the appropriate social class according to the scheme of the Registrar General ${ }^{8}$ by a statistician who was not provided with any other information about the cases. The social class distribution was then compared with that obtained by a proportional analysis of male deaths aged 15-64 in England and Wales, $1970-2,{ }^{9}$ and also of the male population of Britain

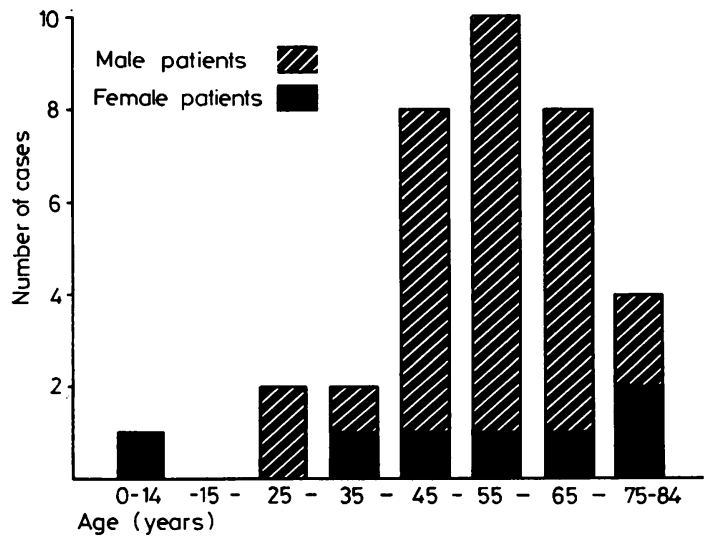

Fig 3 Age-distribution of male and female cases agreed by panel as $A S L, 1963-77$. 
aged 30 and over as determined in the 1971 census. ${ }^{10}$ The observed and expected deaths for the combined classes were not significantly different (table 3),

Table 3 Observed and expected numbers of deaths from ASL by social class for all male cases agreed as ASL (1963-77)

\begin{tabular}{llcc}
\hline Social class & $\begin{array}{l}\text { Observed No Expected No } \\
\text { of deaths }\end{array}$ & $\begin{array}{l}\text { Expected No } \\
(1971 \text { Census) }\end{array}$ \\
\hline $\begin{array}{l}\text { (Deaths } \\
(1970-72)^{8}\end{array}$ & $5 \cdot 3$ & $7 \cdot 0$ \\
I and II & 4 & $13 \cdot 4$ & $13 \cdot 2$ \\
III (Non-manual & 14 & $9 \cdot 3$ & $7 \cdot 8$ \\
and manual) & 10 & 28.0 & 28.0 \\
IV and V & 28 & 5 & \\
Total & &
\end{tabular}

irrespective of whether the cases were of known or unknown aetiology. None of the cases was allocated to social class II, however, and all four cases in social class I had been designated as engineers.

\section{GEOGRAPHICAL DISTRIBUTION}

Plotting the last places of residence for the agreed cases showed a cluster of six cases due to Thorotrast in the Edinburgh area. ${ }^{32}$ The use of Thorotrast in Britain was pioneered in Edinburgh where its use in intra-arterial angiography from 1933 to 1948 had been greater than at any other British centre.

The two men who had been occupationally exposed to vinyl chloride in the manufacture of PVC died in separate parts of the country near the two factories in which they had worked, but another man, unconnected with the chemical industry, had lived for six years before his death within half a mile of one of these factories. ${ }^{1}$

The widespread distribution of the cases of unknown or doubtful aetiology (fig 4) might be explained as following the pattern of the general population, though two cases had lived in Sheffield, a city with a population of about half a million. The occupations and residences of these two men were unrelated, however.

The locations of factories where copper and zinc were smelted or refined were studied for an effect of local pollution by arsenic. ${ }^{11}$ No relation between these factories and the cases of ASL was apparent. Geochemical studies have shown that the area of Britain with the heaviest soil and surface drainage contamination by arsenic and copper is in the counties of Devon and Cornwall (South-west England) as a result of past mining and smelting of arsenical and associated metalliferous ores. ${ }^{12}{ }^{13}$ Only one agreed case of ASL had lived in this area.

\section{OCCUPATION}

Occupational histories of varying completeness were

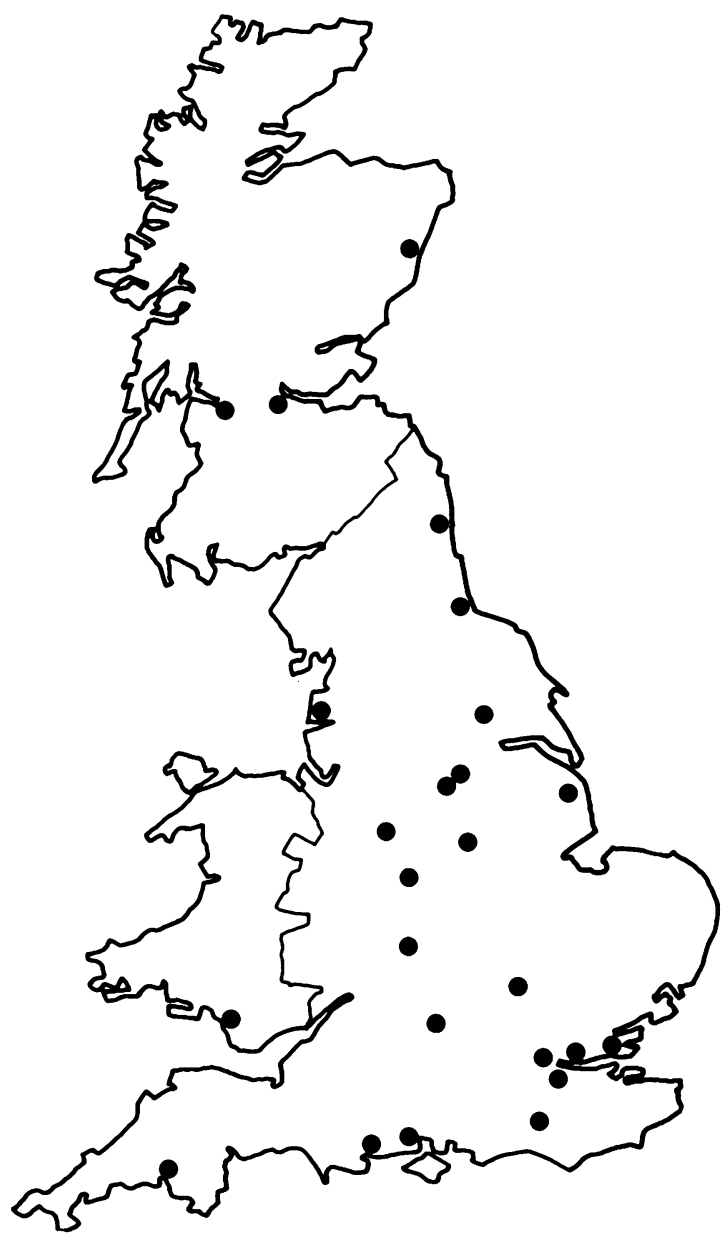

Fig 4 Last places of residence of cases of ASL (agreed by the panel) of unknown or doubtful aetiology.

obtained for $31(91 \%)$ of the adult cases; for the remainder the occupation recorded on the death certificate was accepted. Excluding military service, those industries which appeared in the occupational histories of two or more cases are summarised in table 4. The number who had worked for at least a year in these industries is given, but some of the patients had worked in more than one of the industries shown.

\section{Cases of unknown or doubtful aetiology}

Among the men, the electrical industry was mentioned most often. Four of the six cases had been engineers in different sectors of the industry, and this occupational title had been recorded on their 
Table 4 Industries employing at least two of the agreed adult cases of ASL according to aetiology. (No of cases in parentheses)

\begin{tabular}{lll}
\hline Aetiology & Industry & No of patients \\
\hline $\begin{array}{l}\text { Unknown, or } \\
\text { doubtful (24) } \\
\text { Men (19) }\end{array}$ & & \\
& Electrical & 6 \\
& Plastics fabrication & 3 \\
& Transport & 3 \\
& Construction & 3 \\
& Coal mining & 3 \\
& Farming & 2 \\
& Coke-ovens (gas and & 2 \\
steel) & 2 \\
Women (5) & Cable making & 2 \\
Cinyl chloride (2) & Catering & 2 \\
Men (2) & Domestic service & 2 \\
Thorotrast (8) & PVC manufacture & 2 \\
Men (7) & Transport & 2 \\
& Construction & 2 \\
& Coalmining & 2 \\
\hline
\end{tabular}

death certificates, as mentioned in the results of the social class analysis. Unfortunately, no further information was obtainable for two of these cases; according to the death certificates they had been an electronic testing engineer and power station engineer. The two others, the first a construction and design engineer at a power plant and the second a Post Office engineer supervising telephone and postal power plant, had been in the industry for most of their lives. One of the two remaining cases had been a self-employed electrical fitter all his life, and the other a boilerman and odd job man for the electricity board. It was not possible from the histories obtained to derive a specific exposure which these six men may have had in common. At least three of them, however, probably handled or repaired electrical components for some period in their careers, but more precise information was not available.

Of special interest in relation to vinyl chloride is the finding of three cases among plastics fabricators. According to the death certificates the occupation of two of these men was "machine fitter." The three men had been employed in factories that manufactured goods from raw plastic, including, at some time, PVC; two factories had also produced rubber articles (the use of chloroprene, a possible cause of ASL, ${ }^{14}$ was excluded in one of these firms). The records were inadequate, however, for confirming whether or not these men had come into contact with PVC.

In the construction industry two men had been building labourers and one a clerk. All three men in the transport industry had been road vehicle drivers. Three men had worked in collieries, one as a clerk, another as a "colliery worker" for one year, and the third as a haulage worker for most of his working life.

In the remainder of the industries shown in table 4, farming is noteworthy because of the known use of arsenical pesticides. Both men who had held farming jobs had been labourers at the beginning of their working lives, but details of pesticide usage were unobtainable. Information was provided for one of the two men who had worked in cablemaking; he had been an inspector of brass-plated wire in an entirely non-rubber part of a tyre factory, and was not directly exposed to chemicals or PVC. The other man had been employed in this industry from 1941 to 1946 , before PVC was generally used in cable manufacture. The two men employed in coke ovens had held this occupation for five years and over 30 years.

Of the five women, four had either worked in catering or domestic service for at least five years.

\section{Vinyl chloride cases}

The two men in this category had been process workers in the manufacture of PVC for three and a half years ${ }^{5}$ and 20 years $^{15}$; their ages at death were 37 and 71. Both had worked in autoclaves, where exposure to VCM would have exceeded $200 \mathrm{ppm}$. Neither had been employed in occupations where heavy exposure to PVC dust could have occurred.

\section{Thorium dioxide cases}

Transport and construction industries also feature in this category. The two men in coalmining had been faceworkers, and an injury at work to one had resulted in his receiving Thorotrast during further medical investigations.

\section{Other cases}

Occupations mentioned only once did not show any aetiological pattern. In the infant case, occupational histories were obtained from both parents to study the possible role of transplacental carcinogens. The father had worked for three years in market gardening, followed by three years as a mechanic and painter of old vehicles. He then worked as a refuse collector a year before and after the child was born. The mother had worked as a hairdresser since leaving school until she was seven months' pregnant. She admitted having received heavy exposures to hair lacquer from hand-pumped sprays, and had rarely used canned aerosols at work.

\section{MEDICATIONS}

Of the agreed cases, seven men and one woman had been neurosurgical patients investigated with intraarterial Thorotrast 28-36 years before their deaths. Another woman, who died aged 70, was suspected, 
but not proved, to have suffered from chronic arsenical intoxication. According to the medical records, for five to ten years before her terminal illness she had noticed the development of warty growths on both hands together with thickening of the skin of the palms and soles, which was diagnosed as hyperkeratosis. The histological appearances of the skin were considered to be compatible with arsenic poisoning, but nail and hair clippings analysed for arsenic were negative. Her general practitioner records were obtainable for only the last decade of her life, so it was not possible to exclude the taking of arsenical medication before then. In none of the other cases was treatment with arsenical drugs mentioned, but for most of the older cases this possibility could not be excluded because of the paucity of the available medical records.

Other drugs were noted if they had been prescribed on a regular basis at least several years before the onset of the final illness. Four patients had taken phenobarbitone; one of these, a Thorotrast case, for most of his life to prevent convulsions. Chlorpropamide, tricyclic antidepressants, sulphasalazine, methedrine, guanethidine, and ethinyloestradiol had each been given to different patients. The last drug had been given regularly for at least one to two years to treat hot flushes; the patient died 10 years later aged 71 years. In the infant case the mother had used oral contraception with an interval of one month before becoming pregnant, but no drugs thereafter during her pregnancy.

\section{ALCOHOL AND SMOKING HISTORIES}

Information on alcohol consumption was obtained for $24(86 \%)$ of the men. Sixteen of these were stated to have been light or occasional drinkers, but four others, one of whom was a Thorotrast case, were stated to have drunk to excess, two for most of their lives. Two of the women were said to have drunk alcohol only occasionally. Smoking habit was recorded in 23 men, 17 of whom were stated to have been regular cigarette smokers at some time in their lives, nine smoking at least 20 cigarettes a day; two only had smoked less than ten a day. Four of the women had a positive history, three having smoked less than ten cigarettes a day.

\section{CLINICAL PRESENTATION AND COURSE OF}

\section{ILLNESS}

Clinical details were available either from medical records or published case reports for all but two patients. For all patients a pathologist's report was obtained. In the non-Thorotrast adult cases chronic abdominal pain, mainly in the epigastrium or right hypochondrium, was the commonest presenting symptom and was found in 13 patients, eight of these also having symptoms of a hepatic mass. In four other patients admission to hospital was precipitated by acute abdominal pain, and two more complained of pruritus. For the remainder, the separate reasons for each seeking medical assistance were: jaundice, failure to gain weight after surgery for duodenal ulcer, nasal granuloma, dyspnoea and enlarging abdomen, malaise, and loss of weight. Secondary tumour deposits had caused shortness of breath with haemoptysis and fainting attacks in the presentation of two different patients, the sites concerned being the lungs and heart respectively. Clinical evidence of liver failure was found at initial examination in most cases. The infant presented with a rapidly enlarging hepatic mass at the age of 4 months; the pregnancy had been uneventful, though towards term preeclamptic toxaemia had necessitated induction, followed by a normal delivery (birth weight, $3175 \mathrm{~g}$ ).

Five of the eight Thorotrast patients suffered severe abdominal pain of acute onset, three after premonitory pains over the preceding weeks; four of these patients were diagnosed to have haemoperitoneum. The three remaining patients had complained of loss of weight, two with chronic abdominal pain.

One 49-year-old man was given a liver transplant, but he died three weeks afterwards from peritonitis. Another man underwent a hepatic lobectomy, but he died three months later in liver failure. The clinical course was complicated by microangiopathic haemolytic anaemia in two patients, ${ }^{16} 17$ and both of these underwent splenectomy for this condition. Test results for Australia antigen were recorded in seven cases and were negative, as were the results for alpha-fetoprotein in six cases.

The commonest terminal event was liver failure and its attendant complications. The duration of symptoms preceding admission to hospital was known for 32 adult cases. The median time was about five weeks (range: from a few hours to one year). The length of survival after admission was known for all adults, the median time being three weeks (range: from dead on admission to 15 months). Only three cases lived beyond six months after admission to hospital. The two patients with the shortest duration of symptoms died from haemoperitoneum; both had received Thorotrast.

\section{PATHOLOGICAL DETAILS}

A necropsy had been performed in all but two patients. Haemoperitoneum had caused or contributed towards the death of five Thorotrast cases $(62 \%)$ compared with four of the other adult cases $(15 \%)$, a difference that was statistically significant $(\mathrm{p}=0.03)$.

Extrahepatic metastases were found in eight $(23 \%)$ 
cases, the sites being the spleen in four cases, the lungs in two, and the left atrium and porta hepatis in each of the remaining two. In two of the cases with splenic involvement more distant metastases were found in the bone, peritoneum, and adrenal gland.

In most patients the liver was enlarged by the presence of vascular tumour tissue. Tumour nodules, sometimes raised above the liver surface and containing cavernous or honeycombed areas were often described, as were varying amounts of fibrotic tissue, and macro- or micro-nodular cirrhosis of the liver. In two cases in which the liver was cirrhotic, the presence of a tumour was not confirmed until histological examination. In five Thorotrast cases the spleen was small and fibrotic. The liver of the infant was enormously enlarged and contained multiple umbilicated nodules of tumour tissue on its surface; there were areas of small, thick-walled channels filled with blood surrounded by normal liver tissue, but no extrahepatic metastases, and the immediate cause of death was congestive cardiac failure. In none of these cases was haemochromatosis found.

\section{Discussion}

Excluding the cases of confirmed aetiology, the incidence of ASL during a representative ten-year period was seven a year for all recorded cases, and two a year for cases agreed by the panel, in a British population of about 50 million. Surveys from elsewhere have also shown the rarity of ASL, but they have been undertaken in industrialised countries where the incidence of primary cancer is low, though in Britain it has probably increased slightly over recent decades. ${ }^{18} 19$

Necropsy surveys indicate that ASL accounts for less than $3 \%$ of primary liver tumours and less than 15 per 100000 of all necropsies. ${ }^{20}{ }^{21}$ Epidemiological data in the USA ${ }^{22}$ and the Netherlands ${ }^{23}$ show much the same rate of recorded cases as found in the present study. Infant cases are extremely rare. Out of four recorded infant deaths, tumour tissue was obtained for two, and one of these was agreed as ASL.

The use of data solely from death certificates seemed to provide an insensitive measure of incidence compared with that from all sources, including hospital pathologists, published reports, and cancer registries. The rising trend for all recorded cases for the last years of the study period was not seen for the death certificate cases. Evidently data from death certificates alone cannot be relied on to detect those moderate increases in incidence that may be a clue to new environmental agents. In 17 cases agreed as ASL the death certificate gave a different underlying cause; thus reliance on death certificates could underestimate the true incidence by at least half. In the Thorotrast study ${ }^{32}$ six cases of ASL were eventually identified whereas only three were recorded as ASL on the death certificates; this finding in a virtually complete follow-up of patients with an aboveaverage necropsy rate also suggests that the true incidence could be underestimated by half. On the other hand the panel agreed the diagnosis in under half of all the cases seen, so that incidence rates based on death certificates might not be too far removed from the true incidence, at least among hospital deaths. In Britain about half of all deaths occur in hospital, and on average $20-30 \%$ of these undergo necropsy. ${ }^{24}$ Hepatic cirrhosis and primary liver cancer were the commonest misleading diagnoses, but we have no evidence to suppose that many more cases of ASL were being overlooked in these categories.

The age distribution of the adult cases resembled that of primary liver carcinoma in Britain. ${ }^{18} 25$ There was no conspicuous social class gradient, but surprisingly all four cases in social classes I and II were engineers in the electrical industry. The male:female ratio for adults was 5:1 for all cases, and 4:1 for "idiopathic" cases only. This male preponderance has been shown for primary liver carcinoma ${ }^{25}$ as well as ASL, ${ }^{4}$ suggesting that occupational factors may be responsible. Male susceptibility has been observed in animal studies of primary liver carcinoma, ${ }^{25}$ however, so the importance of occupational agents in these sex differences awaits further elucidation.

The commonest presenting symptom was upper abdominal pain, and in this respect, and also in the time between onset of symptoms and death, ASL resembled primary hepatic carcinoma. ${ }^{18}$ The median survival time of three weeks after admission to hospital emphasises the difficulties in obtaining occupational histories for survey purposes and the necessity of relying on the relatives for this information.

Thus in its incidence and presentation ASL resembled primary hepatic carcinoma, though the number of cases of ASL on which to base these comparisons was small. Extrahepatic metastases, however, were found in only $23 \%$ of cases; this figure should be compared with $47 \%$ obtained by MacSween for primary liver carcinoma in Scotland, ${ }^{18}$ and $69 \%$ reported by Popper et $\mathrm{al}^{4}$ in their cases of ASL, which were mostly drawn from the USA. The reason for our low figure is not clear, but may relate to differences in diagnostic criteria or aetiology.

Rupture of the tumour resulting in intraabdominal haemorrhage caused or contributed towards death in $26 \%$ of adult cases, and was significantly more common in those patients who 
had received Thorotrast. This complication was also found to be frequent in the Portuguese study of Thorotrast patients. ${ }^{26}$ Excluding the Thorotrast cases, haemoperitoneum occurred only in four cases $(15 \%)$. The incidence of rupture in primary hepatic carcinoma has been variously given between $8 \%$ and $14.5 \%$ of all cases, ${ }^{27}$ but MacSween ${ }^{18}$ found an incidence of $2 \%$ only. Our findings, though based on a few patients, suggest that the frequency of this complication in ASL is determined by aetiological as well as other factors.

Known causal agents were confirmed in $29 \%$ of cases, eight of whom had received Thorotrast. Two other deaths were attributable to heavy exposure to vinyl chloride. Among the cases of unknown or doubtful aetiology, three men were suspected of receiving low exposures to vinyl chloride through working with PVC, and another had lived for the last six years of his life within half a mile of a plant that manufactured PVC; three of these four doubtful cases had been originally diagnosed as ASL in years before the publicity over vinyl chloride in 1974. Because of the relatively small size of the plastic fabricating industry, ${ }^{1}$ these findings point to a liver cancer hazard, but in view of the inadequate exposure data, it is impossible to be certain that chemicals other than vinyl chloride may be implicated.

Among the other industries, the electrical industry stands out with six cases, four of whom were engineers and the only cases classified in social classes I and II. Many chemicals are used in the different sectors of this industry, but none was common to all cases. The electrical, transport, construction, and coal-mining industries are among the largest employers, as was farming in the past. The cases found in these industries may not, therefore, be more than expected. Coke ovens and cablemaking are smaller industries, both with a history of cancer hazard, but an excess incidence of liver tumours has not been found in either. ${ }^{28} 29$

The woman suspected of being associated with arsenical medication is so far the only British case of ASL to have been tentatively linked to arsenic exposure. Phenobarbitone had been taken by four patients, but it is a commonly prescribed drug; as an inducer of liver enzymes it might theoretically act in association with a carcinogenic agent to cause ASL.

Among other factors alcohol consumption was recorded as excessive in four patients, but it seems unlikely to be important in the pathogenesis of most cases. A causal relation between hepatitis-B infecticn and the development of hepatocellular carcinoma remains unproved, though an increased prevalence of HBsAg in patients with this carcinoma has been found in Britain as well as other countries. ${ }^{25}$ The results for the HBsAg test were negative in the seven cases in which it had been recorded. The geographical distribution of the cases of doubtful or unknown aetiology did not suggest that local environmental pollution-for example, by arsenic or copper-was important. Contrary to some earlier reports, vinyl chloride was not used as a general anaesthetic in either Britain or the USA.$^{30}$ Before 1974 some aerosol sprays, including those used by hairdressers, contained vinyl chloride as a propellant, ${ }^{30}$ but these sprays were not manufactured in Britain, and thus the mother of the infant patient was unlikely to have received undue exposure to vinyl chloride at work. Contamination of food and drink by very small amounts of residual vinyl chloride in PVC packaging did occur in the past, but the content of residual monomer has now been substantially reduced, ${ }^{31}$ and our findings so far provide no evidence of a hazard to the general public from these earlier exposures.

Unknown at present is the number of British cases of ASL that will eventually arise in those workers who received heavy exposure to vinyl chloride in the past, and whether prophylactic and therapeutic strategies can be devised to deal with the risk should it prove to be substantial. Although the results do not point to any environmental co-carcinogens or promoting agents that might be implicated in the development of ASL, alcohol abuse and drugs acting on the liver should probably be avoided in these workers. The clinical presentation and prognosis of ASL was found to resemble primary liver carcinoma, with upper abdominal pain as the most common symptom. Thus a high index of suspicion is warranted in a patient with a known history of heavy exposure to vinyl chloride who presents with this complaint, and evidence of liver failure should always be sought in such patients. Finally, our findings may be used as a baseline for incidence studies and for evaluating therapeutic advances in the future.

We thank the staff of the Office of Population Censuses and Surveys (England) and the General Register Office (Scotland) for their continuing collaboration. We are grateful to general practitioners, hospital consultants, and medical records officers for their help, especially those pathologists who sent histological material; the next of kin, factory doctors, managers and employees who provided occupational details; and the employment medical and nursing advisers who undertook the interviews.

\section{References}

1 Baxter PJ, Anthony PP, MacSween RNM, Scheuer PJ. Angiosarcoma of the liver in Great Britain, 1963-73. Br Med J 1977;2:919-21. 
${ }^{2}$ Preussman R. Hepatocarcinogens as potential risk for human liver cancer. In: Remmer H, Bolt HM, Bannaslh P, Popper H, eds. Primary Liver Tumours. Lancaster: MTP Press, 1978:11-29.

${ }^{3}$ MacSween RNM, Vetters JM, Ross SK, Ferguson J, Johnstone JM, Sandison AT. Haemangioendothelial sarcoma of the liver. J Pathol 1973;109:39-44.

+ Popper H, Thomas LB, Telles NC, Falk H, Selikoff IJ. Development of hepatic angiosarcoma in man induced by vinyl chloride, Thorotrast and arsenic. Am J Pathol 1978;92:349-70.

${ }^{5}$ Smith PM, Williams DMJ, Evans DMD. Hepatic angiosarcoma in a vinyl chloride worker. Bull NY Acad Med 1976;52:447-52

- Syed S, Jung RT. Cardiac tamponade caused by metastising haemangioendothelial sarcoma of the liver. Brit Heart J 1978;40:697-9.

${ }^{7}$ Fox AF, Collier PF. Mortality experience of workers exposed to vinyl chloride monomer in the manufacture of polyvinyl chloride in Great Britain. $\mathrm{Br} \mathrm{J}$ Ind Med 1977;34:1-10.

${ }^{8}$ Office of Population Censuses and Surveys. Classification of Occupations, 1970. London: HMSO, 1970.

9 Office of Population Censuses and Surveys. Registrar General's Decennial Supplement for England and Wales, 1970-2. London: HMSO, 1978.

10 Office of Population Censuses and Surveys. Census 1971, Great Britain, Economic Activity Part IV. London: HMSO, 1975.

${ }^{11}$ Tarring T, ed. Non-Ferrous Metal Works of the World. 2nd ed. London: Metal Bulletin Books, 1974.

12 Aston SR, Thornton I, Webb JS, Milford BL, Purves JB. Arsenic in stream sediments and waters of South West England. Sci Total Environ 1975;4:347-58.

${ }^{13}$ Colbourn P, Alloway BJ, Thornton I. Arsenic and heavy metals in soils associated with regional geochemical anomalies in South West England. Sci Total Environ 1975;4:359-63.

${ }^{14}$ Infante PF. Mutagenic and carcinogenic risks associated with halogenated olefins. Environ Health Perspect $1977 ; 21: 251-4$.

${ }^{15}$ Lee FI, Harry DS. Angiosarcoma of the liver in a vinylchloride worker. Lancet 1974;1:1316-8.

${ }^{16}$ Donald D, Dawson AA. Microangiopathic haemolytic anaemia associated with malignant haemangio-endothelioma. J Clin Pathol $1971 ; 24: 456-9$.

${ }^{17}$ Pollard SM, Millward-Sadler GH. Malignant haemangio- endothelioma involving the liver. J Clin Pathol 1974;27: 214-21.

${ }^{18}$ MacSween RNM. A clinicopathological review of 100 cases of primary malignant tumours of the liver. $J$ Clin Pathol 1974;27:669-82.

${ }^{19}$ Burnett RA, Patrick RS, Spilg WGS, Buchanan WM, MacSween RNM. Hepatocellular carcinoma and hepatic cirrhosis in the West of Scotland: A 25-year necropsy review. J Clin Pathol 1978;31:108-10.

${ }^{20}$ Alrenga DP. Primary angiosarcoma of the liver. Int Surg 1975;60:198-203.

${ }^{21}$ Rein FR, Huth F. Sechs spontane primäre maligne gefässgeschwülste der leber in einem kollektiv von 30,000 obduktionen. Int Arch Occup Environ Health 1975;34:237-46.

${ }^{22}$ Heath CW, Falk H, Creech JL. Characteristics of cases of angiosarcoma of the liver among vinyl chloride workers in the United States. Ann NY Acad Sci 1975;246:231-6.

${ }^{23}$ Dalderup LM. Angiosarcoma of the liver in Great Britain. Br Med J 1977;2:1149-50.

${ }^{24}$ British Medical Journal. Reviving the hospital necropsy. Br Med J 1977;1:1560.

${ }^{25}$ Johnson PJ, Krasner N, Portmann B, Eddleston ALWF, Williams R. Hepatocellular carcinoma in Great Britain: Influence of age, sex, HBsAg status, and aetiology of underlying cirrhosis. Gut 1978;19:1022-6.

${ }^{26}$ Da Silva Horta J, Da Motta LC, Tavares MH. Thorium dioxide effects in man: Epidemiological, clinical and pathological studies (experience in Portugal). Environ Res $1974 ; 8: 131-59$.

27 Ong GB, Taw JL. Spontaneous rupture of hepatocellular carcinoma. Br Med J 1972;4:146-9.

${ }^{28}$ Doll R, Vessey MP, Beasley RWR, et al. Mortality of gasworkers-final report of a prospective study. Br J Ind Med 1972;29:394-406.

${ }^{29}$ Health and Safety Executive. Mortality in the British Rubber Industries. London: HMSO (in press).

${ }^{30}$ Milby TH, ed. Vinyl Chloride: an information resource. United States: DHEW, 1978.

${ }^{31}$ Ministry of Agriculture, Fisheries and Food. Survey of vinyl chloride content of polyvinyl chloride for food contact and of foods. London: HMSO, 1978.

32 Baxter PJ, Langlands AO, Anthony PP, MacSween RNM, Scheuer PJ. Angiosarcoma of the liver: a marker tumour for the late effects of Thorotrast in Great Britain. Br $J$ Cancer (in press). 